\title{
Influence of Temperature and Photoperiod on the Fecundity of Habrobracon hebetor Say (Hymenoptera: Braconidae) and on the Paralysis of Host Larvae, Plodia interpunctella (Hübner) (Lepidoptera: Pyralidae)
}

\author{
George N. Mbata ${ }^{1, *}$, Sanower Warsi ${ }^{1,2}$ (D) and Mark E. Payton ${ }^{3}$ \\ 1 Agricultural Research Station, Fort Valley State University, Fort Valley, GA 31030, USA; szw0132@auburn.edu \\ 2 Department of Entomology and Plant Pathology, 301 Funchess Hall, Auburn University, \\ Auburn, AL 36849, USA \\ 3 Department of Biomedical Sciences, Rocky Vista University, Parker, CO 80134, USA; mpayton@rvu.edu \\ * Correspondence: mbatag@fvsu.edu
}

\section{check for}

updates

Citation: Mbata, G.N.; Warsi, S.; Payton, M.E. Influence of Temperature and Photoperiod on the Fecundity of Habrobracon hebetor Say (Hymenoptera: Braconidae) and on the Paralysis of Host Larvae, Plodia interpunctella (Hübner) (Lepidoptera: Pyralidae). Insects 2021, 12, 753. https://doi.org/10.3390/insects 12080753

Academic Editor: Mikhail V. Kozlov

Received: 28 July 2021

Accepted: 13 August 2021

Published: 20 August 2021

Publisher's Note: MDPI stays neutral with regard to jurisdictional claims in published maps and institutional affiliations.

Copyright: (c) 2021 by the authors. Licensee MDPI, Basel, Switzerland. This article is an open access article distributed under the terms and conditions of the Creative Commons Attribution (CC BY) license (https:/ / creativecommons.org/licenses/by/ $4.0 /)$.
Simple Summary: This study illustrated the role of optimum temperatures of 25 and $30^{\circ}$ in maximizing oviposition by the female $H$. hebetor. The optimum temperatures for paralysis of $P$. interpunctella larvae by $H$. hebetor were shown to be 28 and $30{ }^{\circ} \mathrm{C}$ at short exposure periods. However, at long exposure periods, the paralysis rates did not differ significantly. Photoperiod had no impact on oviposition or paralysis of $P$. interpunctella by the wasp.

Abstract: Studies were carried out in the laboratory to understand the optimum environmental conditions at which the ectoparasitoid, Habrobracon hebetor Say (Hymenoptera: Braconidae), can paralyze and lay eggs when reared on the larvae of the stored product pest, Plodia interpunctella Hübner (Lepidoptera: Pyralidae). At the four temperatures investigated $\left(20,25,30\right.$, and $\left.35{ }^{\circ} \mathrm{C}\right)$, optimum temperatures for oviposition were found to be 25 and $30{ }^{\circ} \mathrm{C}$, while $35{ }^{\circ} \mathrm{C}$ was the least favorable temperature. No significant differences were found between the percentages of diapausing and non-diapausing larvae paralyzed by the wasp at the temperatures of $20,25,30,35^{\circ} \mathrm{C}$ within 5 days. However, in another experiment that investigated the effect of photoperiods at different temperatures that included 15,19 and $28^{\circ} \mathrm{C}$, the number of paralyzed larvae was highly reduced at low temperatures $\left(15^{\circ} \mathrm{C}\right)$ but photoperiods had no significant impact on the number of host larvae paralyzed. In addition, observations at short time intervals also showed that lower temperatures slowed down host larvae paralysis. The results suggest that $H$. hebetor can paralyze host larvae of $P$. interpunctella more efficiently and deposit more eggs at temperatures within the range of $20-30{ }^{\circ} \mathrm{C}$.

Keywords: Habrobracon hebetor; Plodia interpunctella; fecundity; paralysis; biological control

\section{Introduction}

Several members of the Pyralidae family of the Lepidoptera constitute worldwide pests of postharvest commodities [1]. Larvae of these pyralid moths, particularly the Indian meal moth (Plodia interpunctella Hübner), infest raw commodities such as cereals, dried fruits, vegetables, peanuts, and value-added processed food such as wheat flour [2-5]. Additionally, frass and silk webbing of the larvae can mass commodities together, thereby accelerating the deterioration of stored produce [6,7]. The management of pyralid moths in warehouses, food processing plants, and in other storage structures depends on conventional chemical pesticides, some of which have been found to leave harmful residues in food and the environment [8-11]. In addition, most of the conventional pesticides are facing elimination or restricted use [12,13].

Food safety and environmental concerns are among the factors prompting postharvest pest management experts and warehouse managers to search for safe non-toxic and 
sustainable alternative approaches that can overcome the challenges caused by insect pests [14]. Parasitic wasps represent an alternative and environmentally friendly approach in postharvest systems for the management of pest populations because parasitoids are environmentally safe and do not negatively impact humans or beneficial organisms [14]. Habrobracon hebetor Say (Hymenoptera: Braconidae) is an important ectoparasitoid that has already been demonstrated to have biocontrol potentials and is able to regulate a wide range of stored product moth pests including P. interpunctella [15]. An additional advantage of parasitic wasps is that in some cases, applications of these in postharvest integrated pest management (IPM) reduced insect parts and fragments in commodity [16]. However, rearing large numbers for inundative or inoculative releases in pest management programs has been challenging due to the biology of parasitoid and its host species $[17,18]$.

One of the major challenges in rearing large number of $H$. hebetor is the narrow window of approximately 5 days that the female wasp has to paralyze the host, lay eggs and develop on the host pyralid moth [19]. The 4th and 5th host larvae are the suitable stages for the development of the wasp and these larval stages pupate within days and become unpalatable to the female wasp [19]. Other factors that are likely to enhance the oviposition and development of $H$. hebetor include favorable environmental factors, such as temperature and photoperiods.

Previous studies have examined the effects of temperature on the oviposition, development and parasitism efficiency of $H$. hebetor [20-22]. Habrobracon hebetor laid eggs at the temperature range from 16 to $44^{\circ} \mathrm{C}$ but $30^{\circ} \mathrm{C}$ was the optimum temperature for the maximum egg laying [23]. Similarly, it has been observed that the net fecundity rate and total fecundity rate of $H$. hebetor were high at $30^{\circ} \mathrm{C}$ compared to 20 and $40{ }^{\circ} \mathrm{C}$ [24]. In addition, the maximum number of $H$. hebetor offspring emerged at $30^{\circ} \mathrm{C}$ followed by 40 and $20^{\circ} \mathrm{C}$ [10]. Habrobracon hebetor laid the maximum number of eggs on the 3rd and 5th day of oviposition when fed on diapausing and non-diapausing larvae of $P$. interpunctella, respectively, at $28^{\circ} \mathrm{C}$ and with a 16:8 LD cycle [14]. Additionally, $H$. hebetor had a 0.184 , $0.215,0.261$ and 0.234 innate capacity of increase $\left(\mathrm{r}_{\mathrm{m}}\right)$ values at $20,22,30$ and $40^{\circ} \mathrm{C}$, respectively $[24,25]$. Host parasitism by $H$. hebetor has been shown to vary with the temperature and the level of parasitism sharply decreased with increased temperature [22]. Habrobracon hebetor has been demonstrated to prefer diapausing than non-diapausing larvae for oviposition and development, and a female wasp deposits a mean of 17.46 and 9.64 eggs per day on diapausing and non-diapausing last instars of $P$. interpunctella, respectively [14,15]. However, there is a dearth of information on how combinations of temperature and photoperiod will impact paralysis of $P$. interpunctella larvae by $H$. hebetor and oviposition by the female wasp.

The current study investigated paralysis of the host, P. interpunctella larvae, by the wasp, $H$. hebetor, and oviposition by the wasp at combinations of different temperatures and photoperiods for $48,24 \mathrm{~h}$ and at shorter exposure periods.

\section{Material and Methods}

\subsection{Insect Rearing (Plodia interpunctella and Habrobracon hebetor) in the Laboratory}

Initial cultures of the P. interpunctella and $H$. hebetor used in this study were collected in 2000 and 2001, respectively, from the United States Department of Agriculture, Agriculture Research Station (USDA, ARS) Center for Grain and Animal Health Research (CGAHR), Manhattan, KS 66502, USA, and had since been maintained at Fort Valley State University (FVSU) rearing facility. The laboratory populations of P. interpunctella and H. hebetor had been augmented periodically with field collected moths and wasps, respectively, to avoid problems associated with prolonged laboratory breeding. The artificial diet used to rear the moth was formulated with corn meal, chick starter mash, oats, glycerol and yeast at a volumetric ratio of 4:2:2:1:0.1 [26]. Rearing jars (1 L) containing $P$. interpunctella larvae were kept in chambers maintained at $28 \pm 1.5^{\circ} \mathrm{C} 16 \mathrm{~L}: 8 \mathrm{D}$ (photoperiod) and $70 \pm 5 \% \mathrm{RH}$ to become fully grown, non-diapausing last instar [15]. Ten-d-old (3rd instar) non diapausing larvae were transferred to a chamber maintained at a temperature of $14 \pm 1.5^{\circ} \mathrm{C}, 10 \mathrm{~L}: 14 \mathrm{D}$ 
(photoperiod) to induce diapause in the larvae [27]. For these experiments, 40-d-old diapausing and 18-d-old non-diapausing 5 th instar were used.

The adult parasitoids were fed on fully-grown larvae of P. interpunctella at $28 \pm 1.5^{\circ} \mathrm{C}$, $1 \mathrm{~L} 6: 8 \mathrm{D}$ (photoperiod) and $70 \pm 5 \% \mathrm{RH}$ and the generation time was approximately $20 \mathrm{~d}$ [26]

\subsection{Effect of Temperature on Oviposition of H. hebetor Provisioned with Diapausing and Non-Diapausing P. interpunctella Larvae}

The effect of temperature on the oviposition by $H$. hebetor provisioned with diapausing and non-diapausing larvae was investigated at $20,25,30$ and $35( \pm 0.5){ }^{\circ} \mathrm{C}, 70( \pm 1.5) \% \mathrm{RH}$, 16L: 8D (photoperiod) in cooled incubators, Percival I-36 (Percival, 505 Research Dr., Perry, IA 50220, USA). Oviposition was assessed by counting the number of eggs laid by each female parasitoid wasp under a dissecting microscope. At each temperature, two sets of 5 glass jars $(1000 \mathrm{~mL})$ were prepared, a set with 2 diapausing larvae per jar and the second set with 2 non-diapausing larvae per jar. A pair ( $2 \mathrm{~d}$ old, male and female) of $H$. hebetor was added to each jar. The jars containing P. interpunctella larvae and wasps were transferred to incubators maintained at $20,25,30$ and $35( \pm 0.5){ }^{\circ} \mathrm{C}, 70( \pm 1.5) \% \mathrm{RH}, 16 \mathrm{~L}: 8 \mathrm{D}$ (photoperiod). Every $24 \mathrm{~h}$, the parasitoids were transferred to new jars containing fresh host larvae until the female parasitoid died, while the old jars and host larvae were examined and parasitoid eggs counted. Three trials were carried out with three generations of the wasp and host P. interpunctella.

\subsection{Effect of Temperature on the Paralysis of Diapausing and Non-Diapausing Larvae of P. interpunctella by $\mathrm{H}$. hebetor}

The effect of temperature on the ability of $H$. hebetor to paralyze diapausing and nondiapausing $P$. interpunctella larvae was investigated at $20,25,30$ and $35( \pm 0.5){ }^{\circ} \mathrm{C} ; 70( \pm 1.5)$ $\%$ RH, 16L: 8D (photoperiod). Two sets of 5 jars $(1000 \mathrm{~mL})$ each containing 10 host larvae and a pair ( $2 \mathrm{~d}$ old, male and female) of $H$. hebetor were set up, one set for diapausing larvae and the second set for non-diapausing larvae at each of the temperatures investigated. The jars were transferred to incubators maintained at the desired temperatures $(20,25,30$ and $35^{\circ} \mathrm{C}$ ) for $5 \mathrm{~d}$. Thereafter, paralyzed host larvae were enumerated and recorded. Paralysis in host larvae was induced by the female wasp injecting venom into the host larvae. Following paralysis, the host larvae became numb and unable to respond to touch with sharp forceps. Three trials were carried out with three different generations of parasitoid and host $P$. interpunctella larvae.

\subsection{Effect of Temperature and Photoperiod on Host Larvae Paralysis within 24 and $48 \mathrm{~h}$ Periods}

The combined effect of temperature and photoperiod on host larvae paralysis caused by the wasp was investigated for non-diapausing larvae of $P$. interpunctella at 15, 19 and 28 $( \pm 0.5)^{\circ} \mathrm{C}$ and three light regimes; alternate light and dark cycle (12L:12D), continuous light (24 LL) and continuous darkness (24 DD). Five jars (1000 mL) were set up at each of the 18 treatments. Ten host larvae and one pair of H. hebetor ( $2 \mathrm{~d}$ old, male and female) were placed in each of $1000 \mathrm{~mL}$ rearing jars. A set of 30 jars dispensed with 10 host larvae and 1 pair of wasps each was set up at each temperature tested. The jars containing host larvae and wasps were placed in incubators maintained at 15,19 and $28^{\circ} \mathrm{C}$ under $12 \mathrm{~h} \mathrm{~L}: 12 \mathrm{~h} \mathrm{D}$, $24 \mathrm{~h} \mathrm{LL}$ and $24 \mathrm{~h}$ DD photoperiods and $70 \pm 5 \% \mathrm{RH}$ in incubators. The distribution of the jars is as follows; at $15^{\circ} \mathrm{C}, 10$ jars each were placed at LL, LD and DD chambers. Paralyzed host larvae in 5 jars at each set of combinations (example $15^{\circ} \mathrm{C}$, LL) were enumerated at $24 \mathrm{~h}$ and remaining 5 jars had paralyzed larvae counted after $48 \mathrm{~h}$. Three trials were carried out with different generations of the wasps.

2.5. Effect of Temperature on the Paralysis of P. interpunctella Larvae by H. hebetor at Short-Term Exposure Periods $(1,2,3,6$ h) under Light or Dark Conditions

Sets of $1000 \mathrm{~mL}$ jars were dispensed with 10 fully grown larvae of $P$. interpunctella and a pair (male and female) $H$. hebetor each. Two sub-sets of 4 jars were transferred to incubators maintained at $14,20,28,30$ and $35( \pm 0.5){ }^{\circ} \mathrm{C}$, and at either light or dark condition. A jar 
was withdrawn from each of the incubators after 1, 2, 3, or $6 \mathrm{~h}$ and the number of paralyzed larvae was counted. A total of 10 trials were carried out with three parasitoid generations.

\subsection{Statistical Analysis}

The variables examined included percentage host larvae paralyzed and number of eggs deposited by the parasitoid. The independent variables in this study were temperature, photoperiods, and larval types (diapausing and non-diapausing host larvae). Data were analyzed using Statistical Analysis System version 9.4 [28]. All percentage data were arcsine of square root transformed before analyses to minimize variances and standardize means [29]. Treatments were constructed as combinations of factors, and simple effects of these factors were analyzed with planned contrasts. The Satterthwaite approximation was used in determining DF for the effect of temperature on lifetime oviposition of wasp provisioned with diapausing and non-diapausing larvae. For the data on the effect of temperature and photoperiod on the paralysis of host larvae at short-term exposure periods, a repeated-measures analysis was conducted using autoregressive period 1 covariance structure. Raw mean percentages and standard errors are reported. Statistical significance was determined by $p<0.05$.

\section{Results}

3.1. Effect of Temperature on the Lifetime Oviposition of H. hebetor Provisioned with Diapausing or Non-Diapausing P. interpunctella Larvae

The numbers of eggs laid by mated female $H$. hebetor depended on the host larval type, diapausing or non-diapausing, and temperature, and these two factors significantly interacted with each other (Tables 1 and 2). Females provisioned with diapausing host larvae laid more eggs than those provisioned with non-diapausing larvae. The highest numbers of eggs were laid at $30^{\circ} \mathrm{C}$, and egg laying by the wasp was significantly better at 20 and $25^{\circ} \mathrm{C}$ than at $35^{\circ} \mathrm{C}$ (Tables 1 and 2 ).

Table 1. Effect of temperatures on lifetime oviposition of $H$. hebetor provisioned with diapausing or non-diapausing host larvae of $P$. interpunctella.

\begin{tabular}{|c|c|c|}
\hline \multirow{2}{*}{ Temperature $\left({ }^{\circ} \mathrm{C}\right)$} & \multicolumn{2}{|c|}{$\begin{array}{l}\text { Mean Number of Eggs Laid by Parasitoids }( \pm \text { S.E) } \\
\text { (n = Treatment Sample Size) }\end{array}$} \\
\hline & Diapausing Larvae & Non-Diapausing Larvae \\
\hline 20 & $72.2 \pm 4.1 \mathrm{~A} \mathrm{~b}^{*}(15)$ & $34.0 \pm 3.2 \mathrm{~B} \mathrm{c} \mathrm{(15)}$ \\
\hline 25 & $98.4 \pm 6.5 \mathrm{~A}^{* *} \mathrm{ab}(15)$ & $68.0 \pm 3.9 \mathrm{~B} \mathrm{~b}(15)$ \\
\hline 30 & $120.0 \pm 5.3 \mathrm{~A} \mathrm{a} \mathrm{(15)}$ & $80.8 \pm 3.4 \mathrm{~B}$ a (15) \\
\hline 35 & $41.0 \pm 2.2 \mathrm{~A} \mathrm{c} \mathrm{(15)}$ & $17.6 \pm 1.5$ B c (15) \\
\hline
\end{tabular}

${ }^{*}$ Means within a column followed by the same lowercase letter are not significantly different $(p<0.05)$; ${ }^{* *}$ means within a row with the same uppercase letter are not significantly different $(p<0.05)$; mean separation was by the Tukey-Kramer HSD mean comparison procedure at $\alpha=0.05$.

Table 2. ANOVA results for the main effects of temperature and host larvae type (diapausing and non-diapausing host larvae) of Plodia interpunctella on the fecundity of Habrobracon hebetor.

\begin{tabular}{cccc}
\hline ANOVA & $p$ Value & DF & F Value \\
\hline Larval type & $<0.0001$ & $1,84.3$ & 57.01 \\
Temperature & 0.0001 & $3,81.2$ & 81.10 \\
Larval type $\times$ Temperature & 0.0009 & $3,81.9$ & 6.08 \\
\hline
\end{tabular}

DFs were based on the Satterthwaite approximation; significance level at $5 \%$.

\subsection{Effect of Temperature on of Paralysis of Diapausing and Non-Diapausing Larvae of $P$. interpunctella by $H$. hebetor}

The percentages of both diapausing and non-diapausing larvae paralyzed at all the temperatures investigated ranged between $85.3 \%$ and $96.8 \%$ and were not statistically 
different (Tables 3 and 4). A five-day period was enough time for nearly all the host larvae to be paralyzed at the host density of the current study.

Table 3. Effect of temperature on the paralysis of P. interpunctella by mated female wasp.

\begin{tabular}{ccc}
\hline \multirow{2}{*}{ Temperature $\left({ }^{\circ} \mathbf{C}\right)$} & \multicolumn{2}{c}{ Host Paralyzed (Means \pm S.E) $(\mathbf{n}=$ Treatment Sample Size) } \\
\cline { 2 - 3 } & Diapausing Larvae & Non-Diapausing Larvae \\
\hline 20 & $93.9 \pm 2.4$ a * A (15) & $90.6 \pm 1.5$ a A $(15)$ \\
25 & $96.8 \pm 1.8$ a A ** (15) & $96.4 \pm 1.4$ a A $(15)$ \\
30 & $89.8 \pm 2.0$ a A $(15)$ & $85.2 \pm 1.7$ a A (15) \\
35 & $85.3 \pm 3.0$ a A (15) & $85.5 \pm 1.5$ a A $(15)$ \\
\hline
\end{tabular}

* Means within a column followed by the same lowercase letter are not significantly different using the TukeyKramer HSD mean comparison procedure at $\alpha=0.05 .{ }^{* *}$ Means within a row followed by the same uppercase letter are not significantly different using the Tukey-Kramer HSD mean comparison procedure at $\alpha=0.05$.

Table 4. ANOVA results for the main effects and interactions of type of larvae (diapausing and non-diapausing host larvae) and photoperiods at $19{ }^{\circ} \mathrm{C}$ on host mortality and parasitoid progeny production.

\begin{tabular}{cccc}
\hline Variables & \multicolumn{3}{c}{ Host Mortality } \\
\hline Source & DF & F & $p$ \\
\hline Larval type & 1,112 & 2.51 & 0.06 \\
\hline Temperature & 3,112 & 19.30 & 0.09 \\
\hline Larval type $\times$ temperature & 3,112 & 1.00 & 0.3941 \\
\hline
\end{tabular}

3.3. Interaction of Temperature and Photoperiod on the Paralysis of Host Larvae by H. hebetor within 24 and $48 \mathrm{~h}$ Periods

Temperature had a significant effect on the paralysis of host larvae and the highest percentage of paralyzed host larvae was observed at $28^{\circ} \mathrm{C}$, while the lowest was at $15^{\circ} \mathrm{C}$ (Tables 5 and 6). However, photoperiod did not have any impact on the ability of $H$. hebetor to paralyze $P$. interpunctella larvae (Tables 5 and 6 ). Longer exposure period of $48 \mathrm{~h}$ favored paralysis of the host larvae by the female wasp as the percentages of paralyzed larvae at $48 \mathrm{~h}$ were significantly higher than those paralyzed within $24 \mathrm{~h}$ period (Tables 5 and 6). Statistical analysis did not show any interaction between photoperiod and temperature (Tables 5 and 6).

Table 5. Influence of photoperiod and temperatures on the paralysis of host larvae by $H$. hebetor after 24 and $48 \mathrm{~h}$.

\begin{tabular}{|c|c|c|c|c|c|c|}
\hline \multirow{3}{*}{$\begin{array}{l}\text { Photoperiod } \\
\text { (h) }\end{array}$} & \multicolumn{6}{|c|}{ Mean \% Host Mortality $( \pm$ S.E. $)(n=$ Treatment Sample Size $)$} \\
\hline & \multicolumn{2}{|c|}{$15^{\circ} \mathrm{C}$} & \multicolumn{2}{|c|}{$19{ }^{\circ} \mathrm{C}$} & \multicolumn{2}{|c|}{$28^{\circ} \mathrm{C}$} \\
\hline & $24 \mathrm{~h}$ & $48 \mathrm{~h}$ & $24 \mathrm{~h}$ & $48 \mathrm{~h}$ & $24 \mathrm{~h}$ & $48 \mathrm{~h}$ \\
\hline 12L: $12 \mathrm{~L}$ & $\begin{array}{c}21.0 \pm 2.6 \\
a * D(15)\end{array}$ & $\begin{array}{c}61.0 \pm 4.5 \\
\text { a B (15) }\end{array}$ & $\begin{array}{c}33.0 \pm 3.7 \\
\text { a D (15) }\end{array}$ & $\begin{array}{l}74.0 \pm 4.4 \\
\text { a A B (15) }\end{array}$ & $\begin{array}{c}47.0 \pm 4.7 \\
\mathrm{~b} C(15)\end{array}$ & $\begin{array}{c}86.0 \pm 3.5 \\
\text { a A (15) }\end{array}$ \\
\hline 12L: 12D & $\begin{array}{l}27.0 \pm 3.4 \\
a^{* * *}(15)\end{array}$ & $\begin{array}{c}63.0 \pm 3.9 \\
\text { a B (15) }\end{array}$ & $\begin{array}{c}46.0 \pm 5.0 \\
\text { a C (15) }\end{array}$ & $\begin{array}{c}84.0 \pm 3.0 \\
\text { a A (15) }\end{array}$ & $\begin{array}{l}55.0 \pm 4.8 \\
\text { a b C (15) }\end{array}$ & $\begin{array}{c}97.0 \pm 1.7 \\
\text { a A (15) }\end{array}$ \\
\hline 12D: $12 \mathrm{D}$ & $\begin{array}{c}21.0 \pm 3.1 \\
\text { a } E(15)\end{array}$ & $\begin{array}{l}68.0 \pm 4.7 \\
\text { a B C (15) }\end{array}$ & $\begin{array}{c}34.0 \pm 4.7 \\
\text { a D (15) }\end{array}$ & $\begin{array}{c}76.0 \pm 4.3 \\
\text { a B (15) }\end{array}$ & $\begin{array}{c}61.0 \pm 4.4 \\
\text { a C (15) }\end{array}$ & $\begin{array}{c}98.0 \pm 4.3 \\
\text { a A (15) }\end{array}$ \\
\hline
\end{tabular}

* Means within a column followed by the same lowercase letter are not significantly different using the TukeyKramer HSD mean comparison procedure at $\alpha=0.05 .{ }^{* *}$ Means within a row followed by the same uppercase letter are not significantly different using the Tukey-Kramer HSD mean comparison procedure at $\alpha=0.05$. 
Table 6. ANOVA results for the main effects and interactions of photoperiod and temperatures on the paralysis of host larvae by H. hebetor after 24 and $48 \mathrm{~h}$.

\begin{tabular}{cccc}
\hline Source & DF $^{*}$ & F & $p$ \\
\hline Temperature & 2,238 & 391.68 & $<0.001$ \\
\hline Photoperiod & 2,238 & 2.51 & 0.09 \\
\hline Exposure Period (EP) & 1,238 & 1645.82 & $<0.0001$ \\
\hline Temperature $\times$ Photoperiod & 4,238 & 3.09 & 0.07 \\
\hline EP $\times$ Photoperiod & 2,238 & 3.70 & 0.0263 \\
\hline Temperature $\times$ EP & 4,238 & 15.39 & $<0.0001$ \\
\hline Temperature $\times$ EP $\times$ Photoperiod & 4,238 & 3.29 & $<0.0119$ \\
\hline${ }^{*}$ DF for replication $=14$. & & &
\end{tabular}

3.4. Effect of Temperature on the Paralysis of P. interpunctella Larvae by H. hebetor at Short-Term Exposure Periods $(1,2,3,6$ h) under Light or Dark Conditions

Temperature had a significant effect on the ability of $H$. hebetor to paralyze the host larvae at short exposure periods (Tables 7 and 8). Moderately high temperatures (28 and $30{ }^{\circ} \mathrm{C}$ ) favored paralysis of host larvae by the wasp compared with low temperatures (14, $\left.20^{\circ} \mathrm{C}\right)$ and high temperature $\left(35^{\circ} \mathrm{C}\right)$. Dark and light conditions did not have effect on the percentage of host larvae paralyzed by the wasp but there was a significant interaction between temperature and light/dark conditions (Tables 7 and 8). The percentages of paralyzed host larvae increased with the duration of exposure of host larvae to wasps (Tables 7 and 8 ). The least percentage of paralyzed host larvae by the wasps occurred after $1 \mathrm{~h}$ exposure period, while the highest percentages of paralyzed host larvae were at $6 \mathrm{~h}$ exposure periods at both light and dark conditions $(p<0.05 ; \mathrm{N}=400$; Tables 7 and 8$)$.

Table 7. Short-term (1, 2, 3 or $6 \mathrm{~h})$ effect of temperature and photoperiod on the paralysis of P. interpunctella larvae exposed to $H$. hebetor.

\begin{tabular}{|c|c|c|c|c|c|c|c|c|}
\hline \multirow{4}{*}{$\begin{array}{c}\text { Temperature } \\
\left({ }^{\circ} \mathrm{C}\right)\end{array}$} & \multicolumn{8}{|c|}{ Mean \% Host Mortality $( \pm$ SE) $(\mathrm{n}=$ Treatment Sample Size $)$} \\
\hline & \multicolumn{4}{|c|}{ Light Condition } & \multicolumn{4}{|c|}{ Dark Condition } \\
\hline & \multicolumn{4}{|c|}{ Host Exposure Time (h) } & \multicolumn{4}{|c|}{ Host Exposure Time (h) } \\
\hline & One & Two & Three & Six & One & Two & Three & Six \\
\hline 14 & $\begin{array}{c}5.0 \pm 2.2 \mathrm{C} \\
\mathrm{C}^{*}(10)\end{array}$ & $\begin{array}{c}5.0 \pm 2.2 \mathrm{C} \\
\mathrm{c}(10)\end{array}$ & $\begin{array}{c}13.0 \pm 3.4 \\
C \text { c (10) }\end{array}$ & $\begin{array}{c}48.0 \pm 3.2 \\
\mathrm{~A} \mathrm{~b}(10)\end{array}$ & $\begin{array}{c}5.0 \pm 2.2 \mathrm{C} \\
\quad \mathrm{c}(10)\end{array}$ & $\begin{array}{l}6.0 \pm 2.4 \mathrm{C} \\
\mathrm{c}(10)\end{array}$ & $\begin{array}{c}28.0 \pm 4.8 \mathrm{~B} \\
\mathrm{~b}(10)\end{array}$ & $\begin{array}{c}43.0 \pm 5.0 \\
\mathrm{~A} \mathrm{~b}(10)\end{array}$ \\
\hline 20 & $\begin{array}{c}10.0 \pm 3 . \mathrm{D} \\
\mathrm{bcc}(10)\end{array}$ & $\begin{array}{c}19.0 \pm 4.0 \\
\mathrm{D} \mathrm{b}(10)\end{array}$ & $\begin{array}{c}33.0 \pm 4.7 \\
C b(10)\end{array}$ & $\begin{array}{c}65.0 \pm 2.8 \\
\mathrm{~A} \text { a }(10)\end{array}$ & $\begin{array}{c}10 \pm 3.00 \mathrm{D} \\
\mathrm{bcc}(10)\end{array}$ & $\begin{array}{c}19.0 \pm 3.92 \\
\mathrm{D} \mathrm{b}(10)\end{array}$ & $\begin{array}{c}34 \pm 4.73 \mathrm{C} \\
\mathrm{b}(10)\end{array}$ & $\begin{array}{c}57.0 \pm 4.7 \mathrm{~B} \\
\mathrm{a}(10)\end{array}$ \\
\hline 28 & $\begin{array}{c}15.0 \pm 3.5 \mathrm{E} \\
\text { a b (10) }\end{array}$ & $\begin{array}{c}35.0 \pm 4.7 \\
\mathrm{C} \mathrm{a} \mathrm{(10)}\end{array}$ & $\begin{array}{c}54.0 \pm 4.9 \mathrm{~B} \\
\mathrm{C} \mathrm{a}(10)\end{array}$ & $\begin{array}{c}71.0 \pm 3.5 \\
\mathrm{~A} \text { a }(10)\end{array}$ & $\begin{array}{c}15.0 \pm 3.5 \mathrm{E} \\
\mathrm{a} \mathrm{b} c(10)\end{array}$ & $\begin{array}{c}35.0 \pm 4.7 \\
\mathrm{D} \text { a }(10)\end{array}$ & $\begin{array}{c}47.0 \pm 4.9 \\
\mathrm{C} \mathrm{a}(10)\end{array}$ & $\begin{array}{c}61.0 \pm 4.5 \mathrm{~B} \\
\mathrm{a}(10)\end{array}$ \\
\hline 30 & $\begin{array}{c}21.0 \pm 4.1 \\
\mathrm{C} \mathrm{a}(10)\end{array}$ & $\begin{array}{c}35.0 \pm 4.7 \\
\mathrm{C} \mathrm{a} \mathrm{(10)}\end{array}$ & $\begin{array}{c}59.0 \pm 4.9 \\
\mathrm{~A} \mathrm{a}(10)\end{array}$ & $\begin{array}{c}66.0 \pm 1.9 \\
\mathrm{~A} \text { a }(10)\end{array}$ & $\begin{array}{c}21.0 \pm 4.1 \\
\mathrm{Ca}(10)\end{array}$ & $\begin{array}{c}32.0 \pm 4.6 \\
\mathrm{C} \text { a (10) }\end{array}$ & $\begin{array}{c}44.0 \pm 4.7 \mathrm{~B} \\
\mathrm{a} \mathrm{b}(10)\end{array}$ & $\begin{array}{c}64.0 \pm 4.3 \\
\mathrm{~A} \mathrm{a}(10)\end{array}$ \\
\hline 35 & $\begin{array}{l}5.0 \pm 2.1 \mathrm{D} \\
* * \mathrm{c}(10)\end{array}$ & $\begin{array}{c}6.0 \pm 2.3 \mathrm{D} \\
\mathrm{c}(10)\end{array}$ & $\begin{array}{c}48.0 \pm 4.7 \mathrm{~B} \\
\mathrm{a} \mathrm{b}(10)\end{array}$ & $\begin{array}{c}52.0 \pm 4.9 \\
\mathrm{~A} \mathrm{~b}(10)\end{array}$ & $\begin{array}{l}10.0 \pm 4.0 \\
\mathrm{D} b \mathrm{c}(10)\end{array}$ & $\begin{array}{l}25.0 \pm 4.7 \\
C \text { a b (10) }\end{array}$ & $\begin{array}{c}39.0 \pm 4.8 \mathrm{~B} \\
\mathrm{a} \mathrm{b}(10)\end{array}$ & $\begin{array}{l}56.0 \pm 3.9 \\
\mathrm{~A} \mathrm{~B} \mathrm{a}(10)\end{array}$ \\
\hline
\end{tabular}

${ }^{*}$ Means within a column above followed by the same lowercase letter are not significantly different. ${ }^{* *}$ Means across a row above followed by the same uppercase letter are not significantly different. The Tukey-Kramer HSD means comparison procedure at significance level $p \leq 0.05$. 
Table 8. ANOVA results for the main effects and interactions of short-term $(1,2,3$ or $6 \mathrm{~h})$ effect of temperature and photoperiod on the paralysis of P. interpunctella larvae exposed to H. hebetor.

\begin{tabular}{cccc}
\hline & DF & F Value & $p$ Value \\
\hline Temperature & 4,39 & 90.22 & $<0.0001$ \\
Photoperiod (Light/Dark) & 1,39 & 0.97 & 0.3313 \\
Exposure Period & 4,39 & 1.36 & 0.2557 \\
Temperature $\times$ Photoperiod & 12,39 & 5.81 & $<0.0001$ \\
Temperature $\times$ Exposure Period & 12,39 & 5.81 & $<0.0001$ \\
Photoperiod $\times$ Exposure Period & 3,39 & 20.38 & $<0.0001$ \\
Temperature $\times$ Photoperiod $\times$ Exposure Period & 12,39 & 1.92 & 0.0622 \\
\hline
\end{tabular}

\section{Discussion}

The temperatures at which the highest numbers of eggs were laid by female H. hebetor in the current study were 25 and $30^{\circ} \mathrm{C}$. In a temperature-dependent study of H. hebetor reared on larvae of Galleria mellonella (L.), it was found that temperature range between 25 and $32{ }^{\circ} \mathrm{C}$ favored mass rearing of $H$. hebetor [30]. It is probable that the low progeny production by $H$. hebetor observed outside the optimum temperature range [30] could be due to low oviposition by $\mathrm{H}$. hebetor as was observed at 20 and $35^{\circ} \mathrm{C}$ in the current study. Reduction in oviposition was observed for wasps provisioned with diapausing or nondiapausing host larvae at temperatures outside the optimal range of $20-32{ }^{\circ} \mathrm{C}$. However, the number of eggs laid by wasps provisioned with diapausing host larvae was still higher compared with the number of eggs laid by wasps provisioned with non-diapausing larvae. These results confirm previous observations on the improved oviposition by H. hebetor females provisioned with diapausing $H$. hebetor $[14,15]$.

At temperatures that ranged between 20 and $35^{\circ} \mathrm{C}, \mathrm{H}$. hebetor females paralyzed between 85.2 and $96.8 \%$ host larvae, and these were not significantly different. However, at short exposure periods $(1,2,3$ and $6 \mathrm{~h})$, percentages of larvae paralyzed were significantly different, with more host larvae paralyzed earlier at 28 and $30^{\circ} \mathrm{C}$ than at other temperatures that were investigated. Temperatures outside the optimum range of 25 through $32{ }^{\circ} \mathrm{C}$ were less favorable for host larvae paralysis [30]. Previous studies have documented highest paralyzing efficiency $(\sim 99 \%)$ at $25{ }^{\circ} \mathrm{C}$ [22] and low host larvae paralysis at $35^{\circ} \mathrm{C}$ [20]. In addition, $H$. hebetor high attack rates have been observed at 20, 25 and $30^{\circ} \mathrm{C}$ [21]. High temperatures are likely to cause host larvae to produce a lot of webbing that could shield the host larvae from being paralyzed by the wasps, while low temperatures could slow down movements by the wasp resulting in reduced attacks on host larvae [15]. Since non-optimal low and high temperatures have been demonstrated to reduce rates of paralysis and oviposition by the H. hebetor, is it possible that a delay in host larvae paralysis could reduce oviposition potential of $H$. hebetor? The impact of promptness of host larvae paralysis on the oviposition potential of $H$. hebetor should be investigated.

Photoperiods did not impact the ability of wasps to paralyze host larvae at both long term ( 24 and $48 \mathrm{~h}$ ) and short-term exposure periods. The results suggest that diurnal rhythm may not play a role in the parasitism of host larvae by $H$. hebetor. In addition, visual stimuli may not be among the cues that elicit attack or stinging of the host larvae by $H$. hebetor. Volatile cues emanating from hosts and host habitat have been suggested to be the more likely stimuli that elicit attraction of $H$. hebetor to pyralid larval hosts [31-33].

Author Contributions: Conceptualization, G.N.M. and S.W.; methodology, G.N.M.; software, S.W. and M.E.P.; data curation, S.W. and M.E.P.; writing—original draft preparation, S.W.; writing—review and editing, G.N.M. and M.E.P. visualization, G.N.M.; supervision, G.N.M.; project administration, G.N.M.; funding acquisition, G.N.M. All authors have read and agreed to the published version of the manuscript.

Funding: United States Department of Agriculture, National Institute of Food and Agriculture, Evans Alan Program GEOX-7701.

Institutional Review Board Statement: Not available. 
Data Availability Statement: Data can be provided on request from the lead author.

Acknowledgments: We appreciate a review of an earlier draft of this manuscript by Lambert Kanga, Department of Entomology, Florida A \& M University, Tallahassee, FL 32307, USA. The authors wish to acknowledge Sydnee Shaw, Amber Johnson and Terrica Girdner, Department of Biology, Fort Valley State University, Fort Valley, GA 31030, USA, for technical support. This study was funded in part by a grant from the United States Department of Agriculture, National Institute of Food and Agriculture, Evans Alan Program GEOX-7701.

Conflicts of Interest: The authors declare no conflict of interest.

\section{References}

1. Phillips, T.W.; Berberet, R.; Cuperus, G.W. Postharvest integrated pest management. In Encyclopedia of Food Science and Technology, 2nd ed.; Francis, F.J., Ed.; Wiley: New York, NY, USA, 2000; pp. 2690-2701.

2. Cox, P.D.; Bell, C.H. Biology and ecology of moth pests on stored food. In Ecology and Management of Food-Industry Pests; Gorham, J.R., Ed.; Association of Official Analytical Chemists: Arlington, VA, USA, 1991; pp. 181-193.

3. Johnson, J.A.; Valero, K.A.; Hannel, M.M.; Gill, R.F. Seasonal occurrence of postharvest dried fruit insects and their parasitoids in a culled fig warehouse. J. Econ. Entomol. 2000, 93, 1380-1390. [CrossRef] [PubMed]

4. Mbata, G.N. Preliminary observations on the incidence of insect pests and deterioration in quality of stored groundnuts in some parts of northern Nigeria. Int. J. Trop. Insect Sci. 1987, 8, 15-19. [CrossRef]

5. Mohandass, S.; Arthur, F.H.; Zhu, K.Y.; Throne, J.E. Biology and management of Plodia interpunctella (Lepidoptera: Pyralidae) in stored products. J. Stored Prod. Res. 2007, 43, 302-311. [CrossRef]

6. Abdel-Rahman, H.A.; Hodson, A.C.; Christensen, C.M. Development of Plodia interpunctella (Hb.)(Lepidoptera, Phycitidae) on different varieties of corn at two levels of moisture. J. Stored Prod. Res. 1968, 4, 127-133. [CrossRef]

7. Hamid, A. Static Pressure Drop as Affected by Indian Meal Moth Webbing in Corn. Doctoral Dissertation, Kansas State University, Manhattan, KS, USA, 1990.

8. Tuncbilek, A.S.; Kusmus, A.; Canpolat, U.A.; Ercan, F.S. Effect of UV of radiation on Bracon hebetor (Hymenoptera: Braconidae) and its host larvae, Ephestia kuehniella (Lepidoptera: Pyralidae). Annal. Univ. Craiova Agric. Montanol. Cadastre Ser. 2011, 41, 270-278.

9. Alam, M.; Alam, S.; Miah, M.; Mian, M.; Hossain, M. Mass rearing of Bracon hebetor (Hymenoptera: Braconidae) on wax moth, Galleria mellonella (Lep.: Pyralidae) with varying density of parasitoid and the host. J. Crop. Prot. 2015, 5, 39-48. [CrossRef]

10. Phillips, T.W.; Throne, J.E. Biorational approaches to managing stored-product insects. Ann. Rev. Entomol. 2010, 55, 375-397. [CrossRef]

11. Banks, R.E. Environmental aspects of fluorinated materials. Part 2.'In- kind replacements' for halon fire extinguishants; some recent candidates. J. Fluor. Chem. 1994, 67, 193-203. [CrossRef]

12. Pimentel, D.; Greiner, A.; Bashore, T. Economic and environmental costs of pesticide use. Arch. Environ. Contam. Toxicol. 1998, 21, 84-90. [CrossRef]

13. Mbata, G.N.; Phillips, T.W. Effects of temperature and exposure time on mortality of stored-product insects exposed to low pressure. J. Econ. Entomol. 2001, 94, 1302-1307. [CrossRef] [PubMed]

14. Mbata, G.N.; Warsi, S. Habrobracon hebetor and Pteromalus cerealellae as tools in the postharvest integrated pest management. Insects 2019, 10, 85. [CrossRef] [PubMed]

15. Warsi, S.; Mbata, G.N.; Payton, M.E. Improvement of reproductive performance of Habrobracon hebetor: Consideration of diapausing and non-diapausing larvae of Plodia interpunctella. Biol. Control 2018, 118, 32-36.

16. Flinn, P.W.; Hagstrum, D.W. Augmentative releases of parasitoid wasps in stored wheat reduces insect fragments in flour. J. Stored Prod. Res. 2001, 37, 179-186. [CrossRef]

17. Coudron, T.A.; Ellersieck, M.R.; Shelby, K.S. Influence of diet on long-term cold storage of the predator Podisus maculiventris (Say)(Heteroptera: Pentatomidae). Biol. Control 2007, 42, 186-195. [CrossRef]

18. Chen, H.; Zhang, H.; Zhu, K.Y.; Throne, J. Performance of diapausing parasitoid wasps, Habrobracon hebetor, after cold storage. Biol. Control 2013, 64, 186-194. [CrossRef]

19. Warsi, S.; Mbata, G. Impact of Peanut Depth and Container Size on the Parasitism of Diapausing and Nondiapausing Larvae of Indian Meal Moth (Lepidoptera: Pyralidae) by Habrobracon hebetor (Hymenoptera: Braconidae). Environ. Entomol. 2018, 47, 1226-1232. [CrossRef] [PubMed]

20. Ahmed, M.S.H.; Al-Maliky, S.K.; Al-Taweel, A.A.; Jabo, N.F.; Al-Hakkak, Z.S. Effects of three temperature regimes on rearing and biological activities of Bracon hebetor (Say)(Hymenoptera: Braconidae). J. Stored Prod. Res. 1985, 21, 65-68. [CrossRef]

21. Alikhani, M.; Hassanpour, M.; Golizadeh, A.; Rafiee-Dastjerdi, H.; Razmjou, J. Temperature-dependent functional response of Habrobracon hebetor Say (Hym.: Braconidae) to larvae of Anagasta kuehniella Zeller (Lep.: Pyralidae). In Iranian Plant Protection Congress, 19th ed.; Plant Protection Research Institute: Tehran, Iran, 2010.

22. Noor-ul-Ane, M.; MiRHosseini, M.A.; Crickmore, N.; Saeed, S.; Noor, I.; Zalucki, M.P. Temperature-dependent development of Helicoverpa armigera (Hübner) (Lepidoptera: Noctuidae) and its larval parasitoid, Habrobracon hebetor (Say) (Hymenoptera: Braconidae): Implications for species interactions. Bull. Entomol. Res. 2018, 108, 295-304. [CrossRef] 
23. Genieys, P. Habrobracon brevvicornis Wesm: The effects of the environment and the variation which it produces. Ann. Entomol. Soc. Am. 1924, 18, 143-202. [CrossRef]

24. Singh, D.; Singh, R.P.; Tripathi, C.P.M. Effect of Temperature on life table statistics of Bracon hebetor Say. (Hymenoptera: Braconidae). Int. J. Innov. Appl. Stud. 2014, 7, 497.

25. Nikam, P.K.; Pawar, C.V. Life tables and intrinsic rate of natural increase of Bracon hebetor Say (Hym., Braconidae) population on Corcyra cephalonica Staint.(Lep., Pyralidae), a key parasitoid of Helicoverpa armigera Hbn.(Lep., Noctuidae). J. Appl. Entomol. 1993, 115, 210-213. [CrossRef]

26. Mbata, G.N.; Shapiro-Ilan, D.I. Compatibility of HeteroRHabditis indica (RHabditida: HeteroRHabditidae) and Habrobracon hebetor (Hymenoptera:Braconidae) for biological control of Plodia interpunctella (Lepidoptera: Pyralidae). Biol. Control 2010, 54, 75-82. [CrossRef]

27. Mbata, G.N. Studies on induction of larval diapause in a Nigerian strain of Plodia interpunctella (Hb.) (Lepidoptera: Pyralidae). Int. J. Trop. Insect Sci. 1987, 8, 317-322. [CrossRef]

28. SAS Institute. PROC User's Manual, Version 9.4; SAS Institute: Cary, NC, USA, 2013.

29. Steel, R.G.D.; Torrie, J.H. Principles and Procedures of Statistics: A Biometrical Approach, 2nd ed.; McGraw-Hill: New York, NY, USA, 1980.

30. Forouzan, M.; Amirmaafi, M.; Sahragard, A. Temperature-dependent development of Habrobracon hebetor (Hymenoptera: Braconidae) reared on larvae of Galleria mellonella (Lepidoptera: Pyralidae). J. Entomol. Res. Iran. 2008, 28, 67-78.

31. Fürstenau, B.; Adler, C.; Schulz, H.; Hilker, M. Host habitat volatiles enhance the olfactory response of the larval parasitoid Holepyris sylvanidis to specifically host-associated cues. Chem. Senses 2016, 41, 611-621.

32. Mbata, G.N.; Eason, J.; Payton, M.E.; Davis, M. Putative host volatiles used by Habrobracon hebetor (Hymenoptera: Braconidae) to locate larvae of Plodia interpunctella (Lepidoptera: Pyralidae). J. Insect Behav. 2017, 30, 287-299. [CrossRef]

33. Akinkurolere, R.O.; Boyer, S.; Chen, H.; Zhang, H. Parasitism and host-location preference in Habrobracon hebetor (Hymenoptera: Braconidae): Role of refuge, choice, and host instar. J. Econ. Entomol. 2009, 102, 610-615. [CrossRef] 